\title{
A Characterization for the Flow Behavior of As-Extruded 7075 Aluminum Alloy by the Improved Arrhenius Model With Variable Parameters
}

\author{
Guo-zheng Quan*, Gui-sheng Li, Yang Wang, Wen-quan Lv, Chun-tang Yu, Jie Zhou
}

\author{
School of Material Science and Engineering, Chongqing University, Chongqing 400044, China
}

Received: May 6, 2012; Revised: June 11, 2012

In order to perform the numerical simulations of forging response and establish the processing parameters for as-extruded 7075 aluminum alloy, the compressive deformation behavior of as-extruded 7075 aluminum alloy were investigated at the temperatures of $573 \mathrm{~K}, 623 \mathrm{~K}, 673 \mathrm{~K}$ and $723 \mathrm{~K}$ and the strain rates of $0.01 \mathrm{~s}^{-1}, 0.1 \mathrm{~s}^{-1}, 1 \mathrm{~s}^{-1}$ and $10 \mathrm{~s}^{-1}$ on a Gleeble 1500 thermo-mechanical simulator. Based on the analysis of the effect of strain, temperature and strain rate on flow stress, dynamic recrystallization (DRX) type softening characteristics of the stress-strain curve with single peak were identified. The traditional Arrhenius type model is in favor of the prediction for the flow stress at a fixed strain, and can not satisfy the need of the numerical simulations of various hot forming processes due to the lack of the effect of strain on flow stress. Lin et al. improved Arrhenius type model with a series of variable coefficients as functions of true strain (including activation energy of deformation Q, material constants $\mathrm{n}$ and $\mathrm{a}$, and structure factor $\mathrm{A}$ ) to predict the flow stress during the hot compression. The application has been demonstrated in this work for as-extruded 7075 aluminum alloy. The comparisons between the predicted and experimental results show that, for the worst case, the error in the flow stress estimate is $5.63 \%$, and the max mean error is $3.6 \%$. The developed model provides fast, accurate and consistent results, making it superior to the conventional Arrhenius type model. In further it can be used in computer code to model the forging response of 7075 aluminum alloy mechanical part members under the prevailing loading conditions.

Keywords: flow stress, constitutive equation, material constants, aluminum alloy

\section{Introduction}

Aluminum alloys of the 7075 type (Al-Zn-Mg-Cu) have some advantageous properties that make them an excellent choice for a number of applications in aerospace component manufacture ${ }^{1}$. The understanding of metals and alloys behavior at hot deformation condition has a great importance for designers of hot metal forming processes (hot rolling, forging and extrusion) because of its effective role on metal flow pattern as well as the kinetics of metallurgical transformation, and the constitutive relation is often used to describe the plastic flow properties of the metals and alloys in a form that can be used in computer code to model the forging response of mechanical part members under the prevailing loading conditions ${ }^{2}$. In common, metals and alloys are very sensitive to deformation conditions, the shape of the workpiece and product, the shapes of the tools, friction, temperature, forming speed, etc ${ }^{4}$. In such parameters, the constitutive relationship is one of the most important factors for the analysis problem of metal forming process, and understanding their effects has been a difficult task due to their complex nature ${ }^{3-5}$.

A number of research groups have attempted to develop constitutive equations of materials and suggested their own formulations by putting the experimentally measured data

*e-mail: quangz3000@sina.com into one single equation. Shida ${ }^{6}$ and Misaka ${ }^{7}$ suggested the models giving the stress of carbon steels as a function of the strain, strain rate, temperature and carbon content. Johnson and $\mathrm{Cook}^{8}$ developed a constitutive equation which assumes that the dependence of the stress on the strain, strain rate and temperature can be multiplicatively decomposed into three separate functions that include five constants to be determined by experimental data obtained for a specific material. Lee et al. ${ }^{9}$ established the flow stress constitution equation of 7075 aluminum alloy using a split Hopkinson bar (SHPB) experiment. Jamal et al. ${ }^{10}$ investigated the ANN constitutive model for high strain-rate deformation of Al 7075-T6. The traditional Arrhenius type model is in favor of the prediction for the flow stress at a fixed strain. Due to the lack of the effect of strain on flow stress, it can not satisfy the need of the numerical simulations of various hot forming processes. Lin et $a .^{2}$ introduced a series of variable coefficients (including activation energy of deformation $Q$, material constants $\mathrm{n}$ and a, and structure factor $A$ ) as functions with strain into Arrhenius type model, and then the influence of strain on flow stress were created. Such improved constitutive model was remarkable for its higher accuracy and applied to 42CrMo steel successfully. However, there is still no available information indicating such model applied in as-extruded 7075 aluminum alloy ${ }^{1-8}$. 
The object of this study is to construct the constitutive description equation for as-extruded 7075 aluminum alloy which represents the relationships of strain, temperature, strain rate and flow stress. The main work is to uncover and describe the general nature of the influence of strain on a series of variable coefficients (including activation energy of deformation $Q$, material constants $\mathrm{n}$ and $\mathrm{a}$, and structure factor $A$ ) in Arrhenius type model for as-extruded 7075 aluminum alloy using a series of true stress-strain curves collected from compression tests at the temperature of $573 \sim 723 \mathrm{~K}$ and the strain rate of $0.01 \sim 10 \mathrm{~s}^{-1}$. And then an improved Arrhenius type constitutive equation incorporating a series of polynomial functions for each coefficient was constructed for as-extruded 7075 aluminum alloy. The validity and effectiveness of the proposed equation were also demonstrated by the max mean error of $3.6 \%$ for a fixed strain rate.

\section{Material and Experimental Methods}

The chemical compositions of as-extruded 7075 aluminum alloy (Al-Zn-Mg-Cu) used in this study was as follows (wt. \%): $\mathrm{Zn}-5.5, \mathrm{Mg}-2.2, \mathrm{Cr}-2.2, \mathrm{Cu}-1.7$, Si-0.4, Fe-0.3, Mn-0.1, Al (balance). The homogenized ingot was scalped to diameter $10 \mathrm{~mm}$ and height $12 \mathrm{~mm}$, and seventeen cylindrical specimens were prepared. A computer-controlled servo-hydraulic Gleeble 1500 machine was used for the isothermal compression experiments. The specimens were resistance heated at a heating rate of $1 \mathrm{~K} / \mathrm{s}$ and held at a fixed temperature for $180 \mathrm{~s}$ by thermo-coupled-feedback-controlled AC current, which decreased the anisotropy in flow deformation behavior effectively. Three thermocouples were welded at the mid-span of billet to provide accurate temperature control and measurement during testing. During the tests, the temperatures of specimens were controlled to within $\pm 0.1 \mathrm{~K}$ through three thermocouples adhered to the specimens at the gauge zero. The compression tests corresponding to a height reduction of $60 \%$ were carried out at four different temperatures of $573 \mathrm{~K}, 623 \mathrm{~K}, 673 \mathrm{~K}$ and $723 \mathrm{~K}$ and four different strain rates of $0.01 \mathrm{~s}^{-1}, 0.1 \mathrm{~s}^{-1}, 1 \mathrm{~s}^{-1}, 10 \mathrm{~s}^{-1}$. During the compression process, the variations of stress and strain were monitored continuously by a personal computer equipped with an automatic data acquisition system. The true stress and true strain were derived from the measurement of the nominal stress-strain relationship according to the following formula: $\sigma_{\mathrm{T}}=\sigma_{\mathrm{N}}\left(1+\varepsilon_{\mathrm{N}}\right), \varepsilon_{\mathrm{T}}=\ln \left(1+\varepsilon_{\mathrm{N}}\right)$, where $\sigma_{\mathrm{T}}$ is the true stress, $\sigma_{\mathrm{N}}$ is the nominal stress, $\varepsilon_{\mathrm{T}}$ is the true strain and $\varepsilon_{\mathrm{N}}$ is the nominal strain ${ }^{11}$.

\section{Results and Discussion}

\subsection{Flow stress behavior of as-extruded 7075 Aluminum alloy}

The true stress-strain curves of as-extruded 7075 Aluminum alloy compressed at different deformation conditions are shown in Figure 1a-d. The flow stress as well as the shape of the flow curve is sensitively dependent on temperature and strain rate. The general characteristics of the flow stress curves are similar at all deformation conditions.
For every curve, after a rapid increase in the stress to a peak value, the flow stress decreases monotonically towards a steady state regime with a varying softening rate which typically indicates the onset of DRX. It reveals that 7075 aluminum alloy has an apparent DRX soften characteristic. Comparing these curves with one another, it is found that the stress level decreases with temperature increasing and strain rate decreasing because lower strain rate and higher temperature provide longer time for the energy accumulation and higher mobilities at boundaries which result in the nucleation and growth of dynamically recrystallized grains and dislocation annihilation ${ }^{2,11,12}$.

\subsection{Constitutive equations for flow behavior of as-extruded 7075 aluminum alloy}

So far, several empirical equations have been proposed to determine the deformation activation energy and hot deformation behavior of alloys. The most frequently used is Arrhenius equation which describes the behavior of the material deformed at different temperatures and strain rates. The effects of the temperatures and strain rate on the deformation behavior can be represented by Zener-Hollomon parameter, $Z$ in an exponent-type equation. The hyperbolic law in the Arrhenius type equation gives better approximations between $Z$ parameter and stress ${ }^{13-16}$.

$Z=|\dot{\varepsilon}| \exp (Q / R T)$

$|\dot{\varepsilon}|=A F(\sigma) \exp (-Q / R T)$

where, $F(\sigma)=\left\{\begin{array}{lc}|\sigma|^{n} & \alpha|\sigma|<0.8 \\ \exp (\beta|\sigma|) & \alpha|\sigma|>1.2 \\ {[\sinh (\alpha|\sigma|)]^{n}} & \text { for all } \sigma\end{array}\right.$

in which, $\dot{\varepsilon}$ is the strain rate $\left(\mathrm{s}^{-1}\right), R$ is the universal gas constant $\left(8.31 \mathrm{~J} \cdot \mathrm{mol}^{-1} \cdot \mathrm{K}^{-1}\right), T$ is the absolute temperature $(\mathrm{K})$, $Q$ is the activation energy of DRX $\left(\mathrm{kJ}^{\mathrm{m}} \mathrm{mol}^{-1}\right), \sigma$ is the flow stress (MPa) for a given stain, $A, \alpha$ and $n$ are the material constants, $\alpha=\beta / n$. For the low stress level $(\alpha|\sigma|<0.8)$ and high stress $(\alpha|\sigma|>1.2)$, by substituting power law and exponential law of $F(\sigma)$ into Equation 2, the relationships between flow stress and strain rate can be expressed as following equations respectively

$|\dot{\varepsilon}|=B|\sigma|^{n}$

$|\dot{\varepsilon}|=B^{\prime} \exp (B|\sigma|)$

Where $B$ and $B$ ' are the material constants that are dependent of deformation temperatures.

It is commonly accepted that the effect of strain on stress hasn't been considered in Equation 1-4. Here the effects of deformation strain on stress are investigated by the consideration of the influence of strain on a series of variable coefficients (including activation energy of deformation $Q$, material constants $\mathrm{n}$ and a, and structure 
factor $A$ ) in Arrhenius type model. The following is taking the strain of -0.1 as an example.

\subsubsection{Calculation of the material constants $n, \alpha$ and $\beta$}

By taking the natural logarithm of both sides of Equation 3 and 4, respectively, gives

$\ln |\sigma|=\frac{1}{n} \ln |\dot{\varepsilon}|-\frac{1}{n} \ln B$

$|\sigma|=\frac{1}{\beta} \ln |\dot{\varepsilon}|-\frac{1}{\beta} \ln B^{\prime}$

Then, $\frac{1}{n}=\mathrm{d} \ln |\sigma| / \mathrm{d} \ln |\dot{\varepsilon}|$, and $\frac{1}{\beta}=\mathrm{d}|\sigma| / \mathrm{d} \ln |\dot{\varepsilon}|$. Substituting the values of the flow stress and corresponding strain rate at the strain of -0.1 into the logarithm Equations 5 and 6 gives the relationship between stress and strain rate as shown in Figure 2. Figure $2 \mathrm{a}$, b shows the relationships of $|\sigma|-\ln |\dot{\varepsilon}|$ and $\ln |\sigma|-\ln |\dot{\varepsilon}|$ for $\varepsilon=-0.1$ at the temperatures of $573 \mathrm{~K}$, $623 \mathrm{~K}, 673 \mathrm{~K}$ and $723 \mathrm{~K}$. It can be seen that the stresses under different temperatures and strain rates can be approximated by a group of parallel and straight lines. In Figure 2a the average value of all the lines' slopes is equal to the inverse of $n$-value, thus $n=7.5565 \mathrm{MPa}^{-1}$ for $\varepsilon=-0.1$. Meanwhile

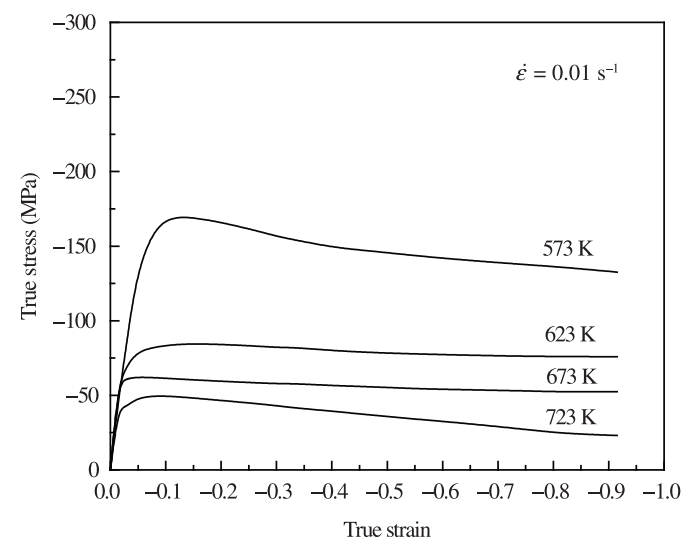

(a)

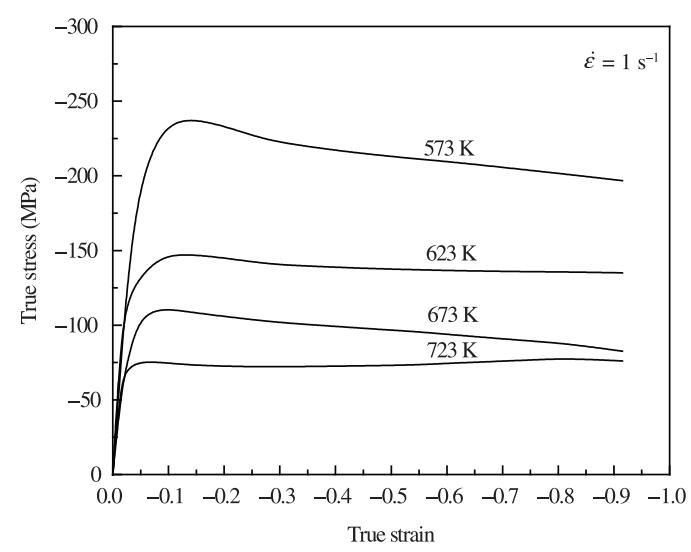

(c) in Figure $2 b$ the average value of all the lines' slopes is equal to the inverse of $\beta$-value, thus $\beta=0.0751 \mathrm{MPa}^{-1}$ for $\varepsilon=-0.1$. Then $\alpha=\beta / n=0.0087$.

\subsubsection{Calculation of the apparent activation energy of deformation $Q$}

The apparent activation energy of deformation is a term defined as the energy that must be overcome in order for the nucleation and growth of new surface or grain boundary to occur. Activation energy may also be defined as the minimum energy required to start DRX, and it can be thought as the height of the potential energy barrier. The apparent activation energy of deformation is usually denoted by $Q$, which an important physical parameter is serving as an indicator of deformation difficulty degree in the plasticity deformation theory. For all the stress level (including low and high stress levels), Equation 2 can be represented as the following:

$|\dot{\varepsilon}|=A[\sinh (\alpha|\sigma|)]^{n} \exp (-Q / R T)$

If $\dot{\varepsilon}$ is constant, there is a linear relationship between $\ln \sinh (\alpha|\sigma|)$ and $1 / T$, and Equation 7 can be rewritten as

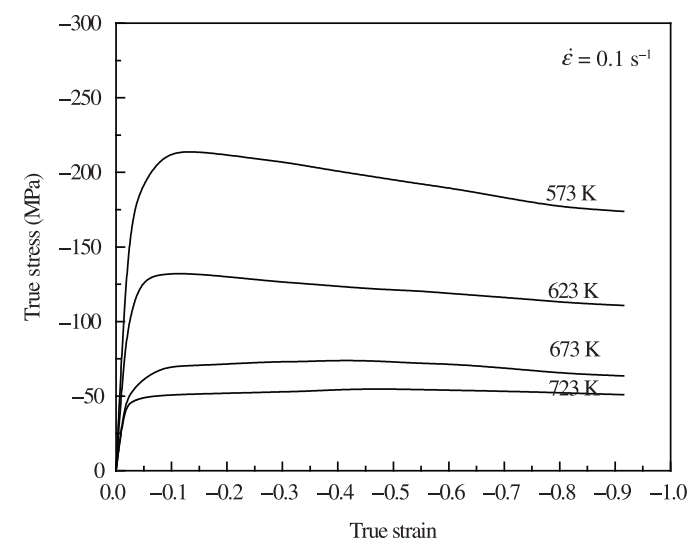

(b)

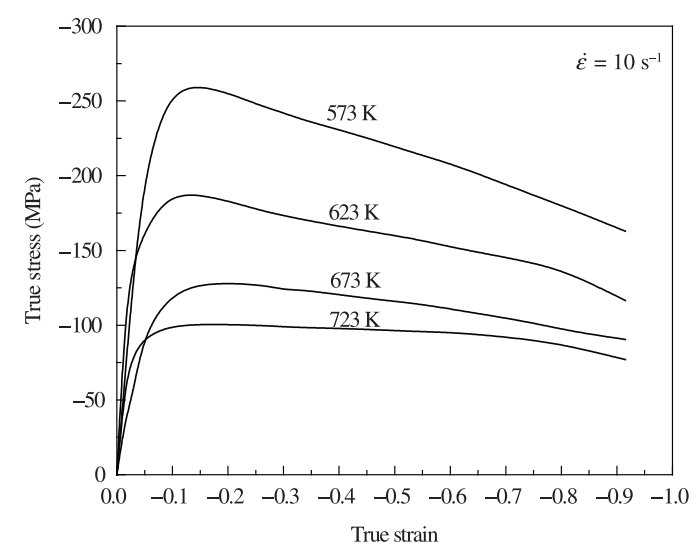

(d)

Figure 1. True stress-strain curves of as-cast 7075 aluminum alloy at different strain rates and temperatures (a) $0.01 \mathrm{~s}^{-1}, 573 \sim 723 \mathrm{~K}$, (b) $0.1 \mathrm{~s}^{-1}, 573 \sim 723 \mathrm{~K}$, (c) $1 \mathrm{~s}^{-1}, 573 \sim 723 \mathrm{~K}$, (d) $10 \mathrm{~s}^{-1}, 573 \sim 723 \mathrm{~K}$. 
$Q=R n\{\mathrm{~d}[\ln \sinh (\alpha|\sigma|)] / \mathrm{d}(1 / T)\}$

The stresses at the strain of -0.1 under different temperatures and strain rates can be identified for the present target stresses. The linear relationships between $\operatorname{In} \sinh (\alpha|\sigma|)$ and $1 / T$ at different strain rates were fitted out as Figure $3 a$. The mean value of all the slope rates is accepted as $Q /(R n)$ value, furthermore $Q$ value for $\varepsilon=-0.1$ are obtained as 96.1749 kJ.mol ${ }^{-1}$.

\subsubsection{Construction of constitutive equation at strain of -0.1}

Taking the logarithm of both sides of Equation 7 gives:

$\ln [\sinh (\alpha|\sigma|)]=\frac{1}{n} \ln |\dot{\varepsilon}|+\frac{Q}{n R T}-\frac{1}{n} \ln A$

By substituting the values of the flow stress and strain rate for all the tested temperatures into Equation 9, the linear relationships between $\ln [\sinh (\alpha|\sigma|)]$ and $\ln |\dot{\varepsilon}|$ at different temperatures were fitted out as Figure $3 \mathrm{~b}$. The mean value of all the intercepts of $\ln [\sinh (\alpha|\sigma|)]$ versus $\ln |\dot{\varepsilon}|$ plots is accepted as $A$ value, furthermore $A$ value for $\varepsilon=-0.1$ are obtained as $2.628 \times 1012 \mathrm{~s}^{-1}$. Substituting $n, \alpha, Q$ and $A$ into Equation 7 gives the relationships between $\dot{\varepsilon}, T$ and $\sigma$ as following.

$$
\begin{aligned}
& |\dot{\varepsilon}|=2.628 \times 10^{12}\left[\sinh (0.0087|\sigma|)^{7.5565}\right] \\
& \exp \left[-\left(96.1749 \times 10^{3}\right) / 8.31 T\right]
\end{aligned}
$$

Substituting Zener-Hollomon parameter $Z=|\dot{\varepsilon}| \exp (Q / R T)$ into Equation 2, thus, the flow stress can be expressed as Equation 11.

$|\sigma|=\frac{1}{\alpha} \ln \left\{(Z / A)^{1 / n}+\left[(Z / A)^{2 / n}+1\right]^{1 / 2}\right\}$

Here, substituting $Z=|\dot{\varepsilon}| \exp \left[\left(96.1749 \times 10^{3}\right) / 8.31 T\right]$, and $A=2.628 \times 10^{12} \mathrm{~s}^{-1}$ into Equation 11, the constitutive equation for flow behavior of as-extruded 7075 aluminum alloy can be expressed as Equation 12 .

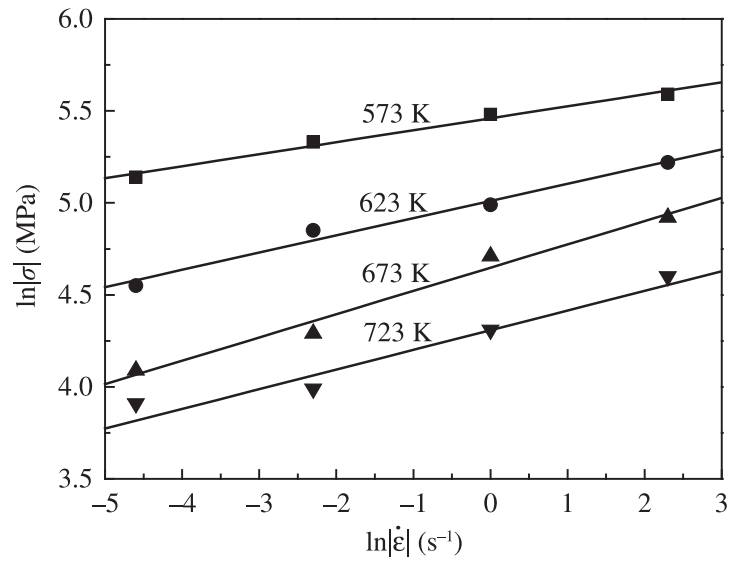

(a)

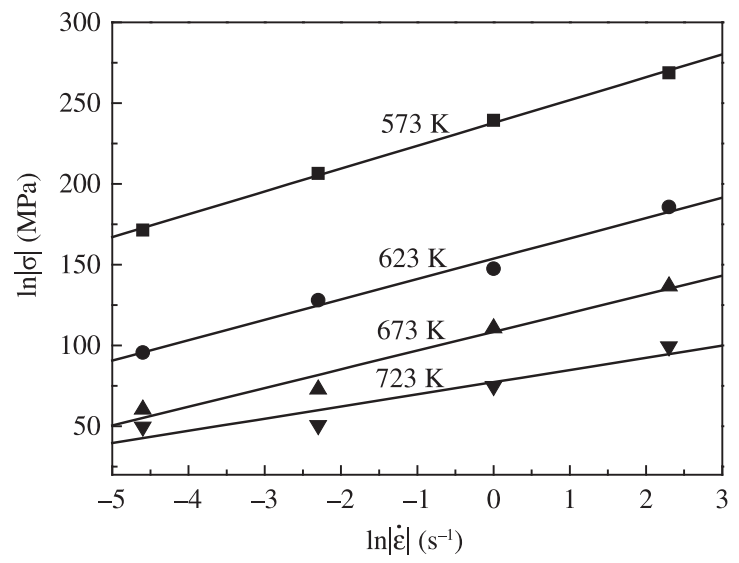

(b)

Figure 2. The relationships between (a) $\ln |\sigma|$ and $\ln |\dot{\varepsilon}|$, (b) $\ln |\sigma|$ and $\ln |\dot{\varepsilon}|$.

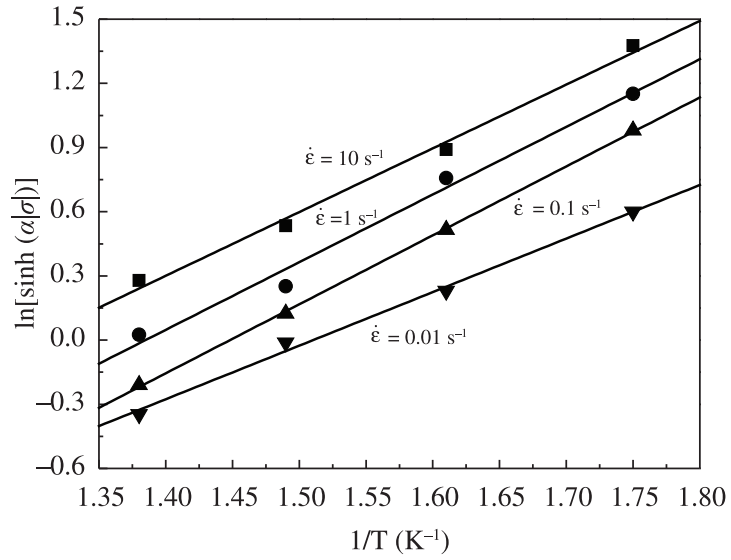

(a)

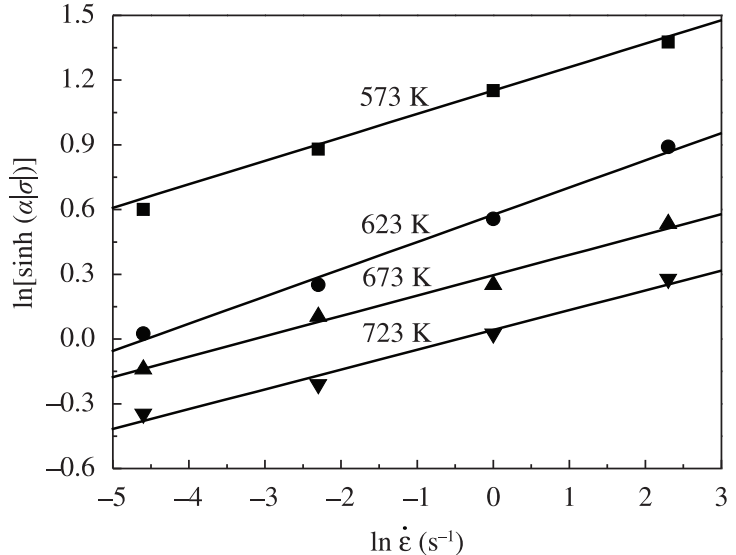

(b)

Figure 3. The relationships between (a) $\ln [\sinh (\alpha|\sigma|)]$ and $T^{-1}$, (b) $\ln [\sinh (\alpha|\sigma|)]$ and $\ln |\dot{\varepsilon}|$. 
$|\sigma|=114.94 \ln \left\{\left\{\frac{|\dot{\varepsilon}| \exp \left[\frac{\left(96.1749 \times 10^{3}\right)}{8.31 T}\right]}{\left(2.628 \times 10^{12}\right)}\right\}^{1 / 7.5565}\right.$
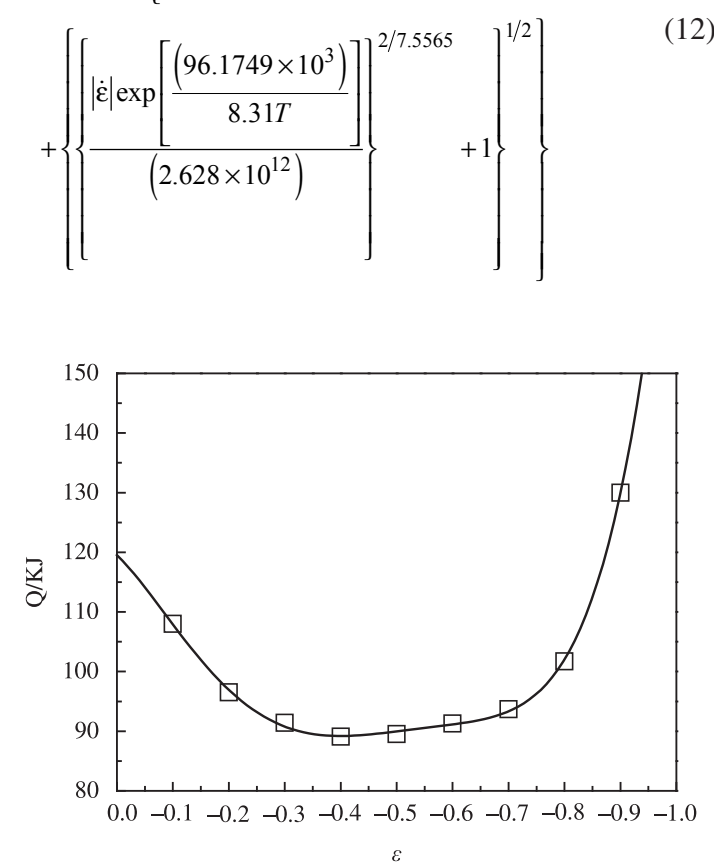

(a)

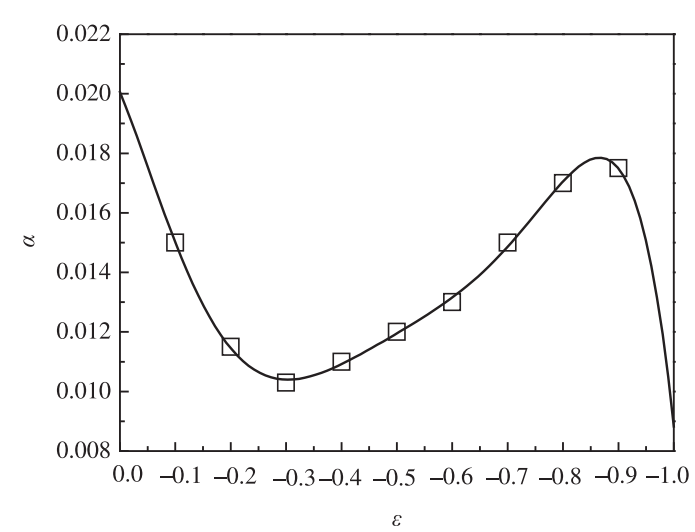

(c)

\subsubsection{Construction of constitutive equation in the strain range of $0 \sim-0.9$}

The above is taking the strain of -0.1 as an example, while the following is about the influence of strain $(0 \sim-0.9)$ with interval of -0.1 on flow stress. A series of variable coefficients (including activation energy of deformation $Q$, material constants $n$, and $\alpha$, and structure factor $A$ ) in Arrhenius type model at different deformation strains within the range of $0 \sim-0.9$ and the interval of -0.1 were computed by the way as above. The relationships between $Q, \ln A, n, \alpha$ and true strain $\varepsilon$ for as-extruded 7075 aluminum alloy were polynomial fitted by the compensation of strain, as shown in Equation 13. The polynomial fitted results of $Q, \operatorname{In} A, n, \alpha$ of

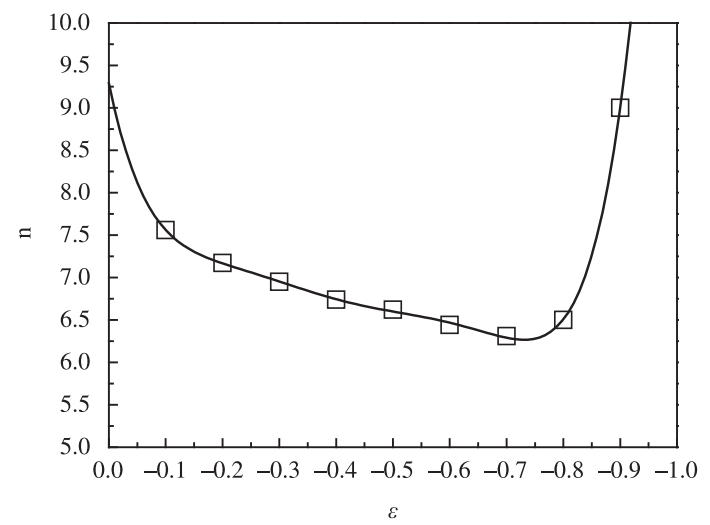

(b)

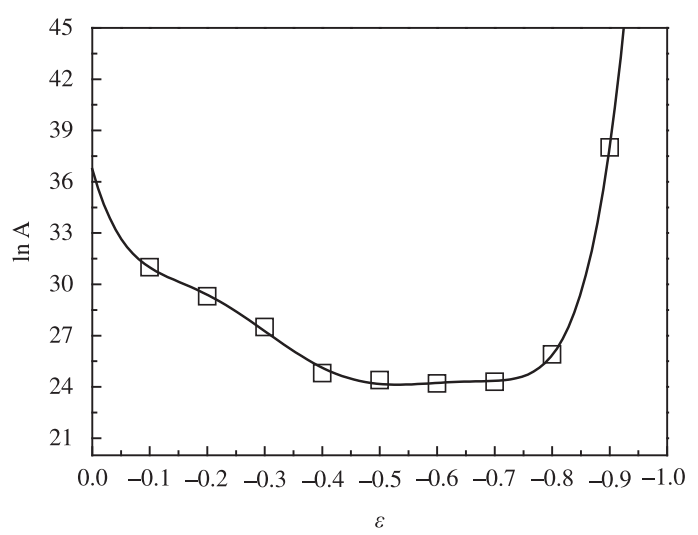

(d)

Figure 4. Relationships between (a) Q, (b) n, (c) a, (d) ln A and true strain by polynomial fit of 7075 aluminum alloy.

Table 1. Polynomial fitting results of $Q, n, \ln A$ and $\alpha$ of 7075 aluminium alloy.

\begin{tabular}{rrrrrrrrr}
\hline & $\boldsymbol{Q}$ & \multicolumn{2}{c}{$\boldsymbol{n}$} & \multicolumn{2}{c}{$\boldsymbol{l n} \boldsymbol{A}$} & \multicolumn{2}{c}{$\boldsymbol{a}$} \\
\hline$B_{0}$ & 119.53 & $C_{0}$ & 9.29 & $D_{0}$ & 36.74 & $E_{0}$ & 0.02 \\
$B_{1}$ & -90.57 & $C_{1}$ & -32.50 & $D_{1}$ & -120.40 & $E_{1}$ & -0.04 \\
$B_{2}$ & -466.16 & $C_{2}$ & 217.29 & $D_{2}$ & 968.02 & $E_{2}$ & -0.17 \\
$B_{3}$ & 2438.20 & $C_{3}$ & -791.47 & $D_{3}$ & -4208.20 & $E_{3}$ & 1.46 \\
$B_{4}$ & -3718.53 & $C_{4}$ & 1539.51 & $D_{4}$ & -8971.23 & $E_{4}$ & -3.39 \\
$B_{5}$ & 1916.67 & $C_{5}$ & -1511.65 & $D_{5}$ & -9098.29 & $E_{5}$ & 3.42 \\
$B_{6}$ & $3.77 \times 10^{-11}$ & $C_{6}$ & 587.96 & $D_{6}$ & 3537.04 & $E_{6}$ & -1.29 \\
\hline
\end{tabular}


as-extruded 7075 aluminum alloy are provided in Table 1. The variation of material constants are shown in Figure 4.

$$
\begin{aligned}
& Q=j(\varepsilon)=B_{0}+B_{1} \varepsilon+B_{2} \varepsilon^{2}+B_{3} \varepsilon^{3}+B_{4} \varepsilon^{4}+B_{5} \varepsilon^{5}+B_{6} \varepsilon^{6} \\
& n=h(\varepsilon)=C_{0}+C_{1} \varepsilon+C_{2} \varepsilon^{2}+C_{3} \varepsilon^{3}+C_{4} \varepsilon^{4}+C_{5} \varepsilon^{5}+C_{6} \varepsilon^{6} \\
& \ln A=\ln f(\varepsilon)=D_{0}+D_{1} \varepsilon+D_{2} \varepsilon^{2}+D_{3} \varepsilon^{3}+D_{4} \varepsilon^{4}+D_{5} \varepsilon^{5}+D_{6} \varepsilon^{6} \\
& \alpha=g(\varepsilon)=E_{0}+E_{1} \varepsilon+E_{2} \varepsilon^{2}+E_{3} \varepsilon^{3}+E_{4} \varepsilon^{4}+E_{5} \varepsilon^{5}+E_{6} \varepsilon^{6}
\end{aligned}
$$

Substituting a, n, $Q$ and $A$ in Equation 13 into Equation 7 gives the relationships between $\dot{\varepsilon}, T$ and $\sigma$ as Equation 14 .

$|\dot{\varepsilon}|=f(\varepsilon)\{\sinh [g(\varepsilon)|\sigma|]\}^{h(\varepsilon)} \times \exp (j(\varepsilon) / 8.31 T)$

Thus, $Z=|\dot{\varepsilon}| \exp [j(\varepsilon) / 8.31 T]$. Furthermore, the constitutive equation for flow behavior of as-extruded 7075 aluminum alloy in a wide strain range of $0 \sim-0.1$ can be expressed as Equation 15.

$|\sigma|=\frac{1}{g(\varepsilon)} \ln \left\{\left(\frac{|\dot{\varepsilon}| \exp [j(\varepsilon) / 8.314 T]}{f(\varepsilon)}\right)^{\frac{1}{h(\varepsilon)}}+\left[\left(\frac{|\dot{\varepsilon}| \exp [j(\varepsilon) / 8.314 T]}{f(\varepsilon)}\right)^{\frac{2}{h(\varepsilon)}}+1\right]^{\frac{1}{2}}\right\}$

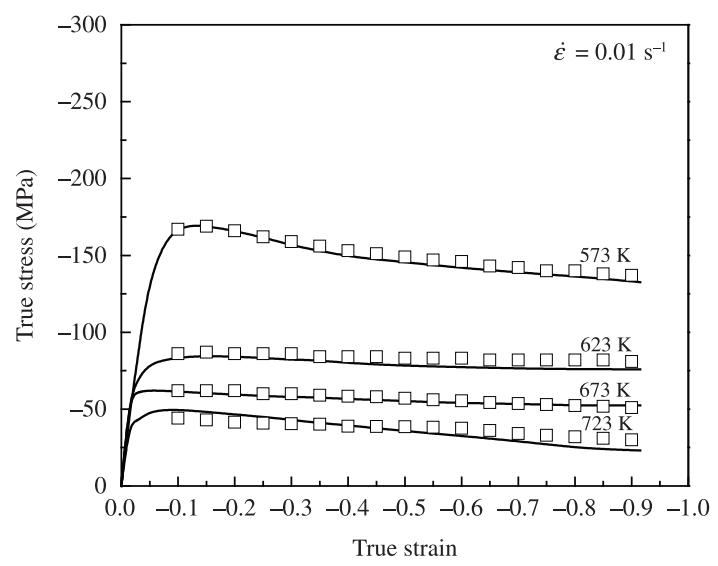

(a)

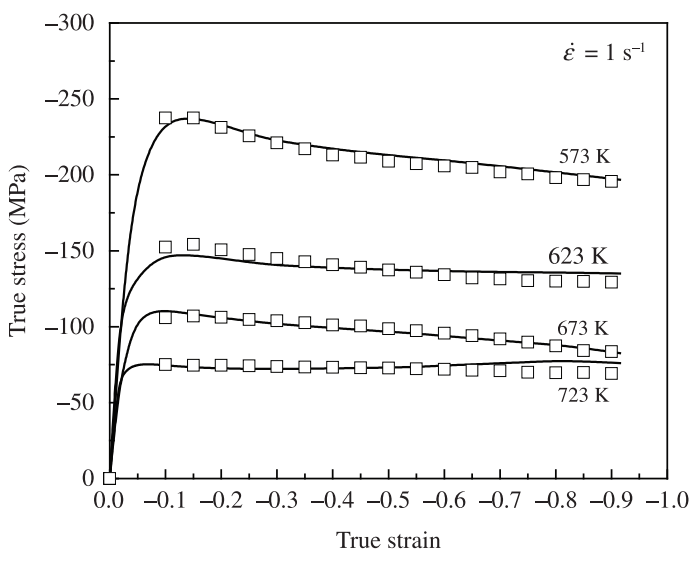

(c) where $f(\varepsilon), g(\varepsilon), h(\varepsilon)$ and $j(\varepsilon)$ are the polynomial functions of $A, \alpha, n$ and $Q$ at different true strains, and their expressions are as Equation 13 and Table 1.

\subsection{Adaptability evaluation of the developed constitutive equation}

In order to verify the developed constitutive equations of 7075 aluminum alloy, the comparison between the experimental and predicted results was carried out. Using the Equation 15, by applying the determined material constants of the constitutive equation and fixed the $\varepsilon, \dot{\varepsilon}, T$, the flow stress can be calculated for strain rates between $0.01 \mathrm{~s}^{-1} \sim 10 \mathrm{~s}^{-1}$ and temperatures between $573 \mathrm{~K} \sim 723 \mathrm{~K}$. Figure 5 shows comparisons between the experimental and predicted results by the developed Equation 15 considering the compensation of strain at the temperatures of $573 \mathrm{~K}, 623 \mathrm{~K}, 673 \mathrm{~K}$ and $723 \mathrm{~K}$, and the strain rates of $0.01 \mathrm{~s}^{-1}, 0.1 \mathrm{~s}^{-1}, 1 \mathrm{~s}^{-1}$ and $10 \mathrm{~s}^{-1}$. It can be seen that the calculation results are well in agreement with the experimental results not only at the strain-hardening stage but also at the strain-softening stage. In order to evaluate the detailed accuracy of the developed constitutive equation of as-extruded 7075 aluminum alloy, the error between the calculated flow stress $\left(\sigma_{\mathrm{C}}\right)$ and

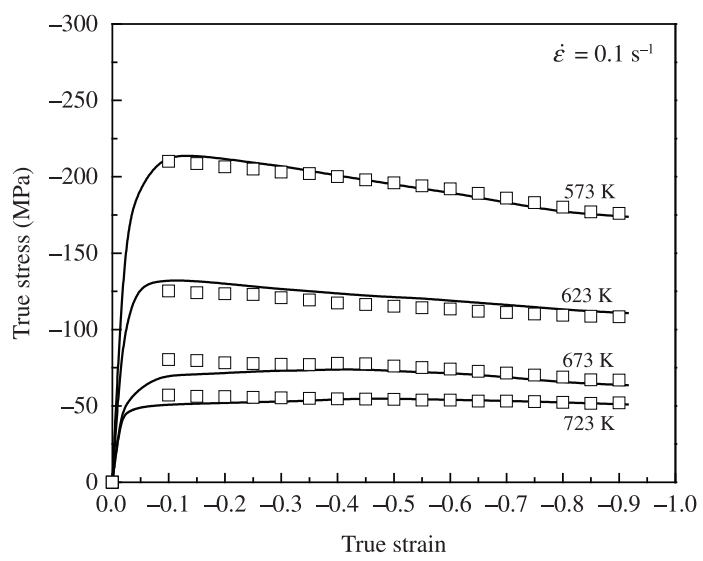

(b)

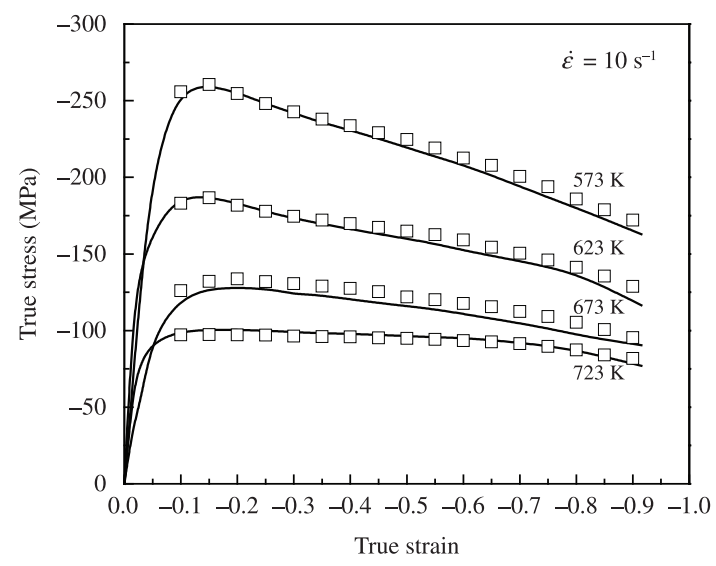

(d)

Figure 5. Comparison between predicted and measured flow stress curves of 7075 aluminum alloy (a) $0.01 \mathrm{~s}^{-1}$, (b) $0.1 \mathrm{~s}^{-1}$, (c) $1 \mathrm{~s}^{-1}$, (d) $10 \mathrm{~s}^{-1}$. 
Table 2. Comparisons between predicted and measured flow stress curves of 7075 aluminium alloy under strain rates of (a) $0.01 \mathrm{~s}^{-1}$ (b) $0.1 \mathrm{~s}^{-1}$ (c) $1 \mathrm{~s}^{-1}$ (d) $10 \mathrm{~s}^{-1}$.

\begin{tabular}{|c|c|c|c|c|c|c|}
\hline$\dot{\varepsilon}\left(s^{-1}\right)$ & $\varepsilon$ & $\mathbf{T}(\mathbf{K})$ & $\left|\sigma_{\mathrm{c}}\right|(\mathbf{M P a})$ & $\left|\sigma_{\mathrm{M}}\right|(\mathbf{M P a})$ & Error\% & Mean \% \\
\hline \multirow[t]{12}{*}{0.01} & -0.3 & 573 & 159.50 & 156.60 & 1.85 & \multirow{12}{*}{$0.65 \%$} \\
\hline & & 623 & 91.5 & 94.1 & -2.74 & \\
\hline & & 673 & 60.36 & 58.04 & 4.00 & \\
\hline & & 723 & 40.59 & 41.89 & -3.09 & \\
\hline & -0.5 & 573 & 149.54 & 145.91 & 2.49 & \\
\hline & & 623 & 87.15 & 89.68 & -2.82 & \\
\hline & & 673 & 56.96 & 54.90 & 3.75 & \\
\hline & & 723 & 39.58 & 38.44 & 2.9 & \\
\hline & -0.7 & 573 & 142.23 & 138.33 & 2.82 & \\
\hline & & 623 & 85.18 & 88.39 & -3.64 & \\
\hline & & 673 & 53.53 & 53.62 & -0.17 & \\
\hline & & 723 & 38.62 & 40.56 & -4.7 & \\
\hline \multirow[t]{12}{*}{0.1} & -0.3 & 573 & 189.86 & 197.55 & -3.90 & \multirow{12}{*}{$-1.56 \%$} \\
\hline & & 623 & 116.82 & 122.05 & -4.29 & \\
\hline & & 673 & 80.16 & 75.89 & 5.63 & \\
\hline & & 723 & 55.19 & 52.74 & 4.63 & \\
\hline & -0.5 & 573 & 177.43 & 185.20 & -4.19 & \\
\hline & & 623 & 121.18 & 117.01 & 3.56 & \\
\hline & & 673 & 76.03 & 75.94 & 0.20 & \\
\hline & & 723 & 54.27 & 54.53 & -0.48 & \\
\hline & -0.7 & 573 & 166.42 & 173.56 & -4.11 & \\
\hline & & 623 & 110.11 & 111.87 & -1.5 & \\
\hline & & 673 & 71.40 & 70.60 & 1.14 & \\
\hline & & 723 & 53.09 & 53.36 & -0.50 & \\
\hline \multirow[t]{12}{*}{1} & -0.3 & 573 & 221.01 & 222.54 & -0.69 & \multirow{12}{*}{$-0.78 \%$} \\
\hline & & 623 & 144.81 & 140.67 & 2.94 & \\
\hline & & 673 & 103.80 & 101.94 & 1.83 & \\
\hline & & 723 & 73.76 & 71.96 & 2.50 & \\
\hline & -0.5 & 573 & 205.88 & 213.00 & -3.34 & \\
\hline & & 623 & 137.36 & 137.63 & -0.20 & \\
\hline & & 673 & 98.67 & 96.48 & 2.27 & \\
\hline & & 723 & 72.81 & 73.02 & -0.29 & \\
\hline & -0.7 & 573 & 190.88 & 188.78 & 1.1 & \\
\hline & & 623 & 130.36 & 135.87 & -4.05 & \\
\hline & & 673 & 91.99 & 91.14 & 0.93 & \\
\hline & & 723 & 70.88 & 73.67 & -3.78 & \\
\hline \multirow[t]{12}{*}{10} & -0.3 & 573 & 252.60 & 248.27 & 1.74 & \multirow{12}{*}{$3.6 \%$} \\
\hline & & 623 & 174.56 & 174.07 & 0.29 & \\
\hline & & 673 & 130.58 & 135.90 & -3.91 & \\
\hline & & 723 & 96.304 & 99.15 & -2.88 & \\
\hline & -0.5 & 573 & 234.62 & 226.26 & 3.70 & \\
\hline & & 623 & 164.86 & 160.68 & 2.60 & \\
\hline & & 673 & 123.88 & 126.58 & -2.13 & \\
\hline & & 723 & 94.89 & 96.52 & -1.69 & \\
\hline & -0.7 & 573 & 215.47 & 209.68 & 2.76 & \\
\hline & & 623 & 154.34 & 146.71 & 5.20 & \\
\hline & & 673 & 114.42 & 115.55 & -0.98 & \\
\hline & & 723 & 91.41 & 92.42 & -1.10 & \\
\hline
\end{tabular}


measured flow stress $\left(\sigma_{\mathrm{M}}\right)$ can be calculated as Equation 16 . Table 2 lists the detailed evaluation results for flow stress at the true strains of $-0.3,-0.5$ and -0.7 , and the strain rates of $0.01 \mathrm{~s}^{-1}, 0.1 \mathrm{~s}^{-1}, 1 \mathrm{~s}^{-1}$ and $10 \mathrm{~s}^{-1}$. It can be easily found that, for the worst case, the error in the flow stress estimate is $5.63 \%$, and the max mean error for a fixed strain rate is $3.6 \%$. The results show that applying improved Arrhenius model with variable parameters to predict the flow stress has higher accuracy degree. The cause lies in that the improved constitutive model with a series of variable coefficients as function of true strain, including activation energy of deformation $Q$, material constants $\mathrm{n}$ and a, and structure factor $A$. Research show that the proposed deformation constitutive equation gives an accurate and precise estimate of the flow stress for as-extruded 7075 aluminum alloy, and can be used to analyze the problems during metal forming process.

$$
\text { Error }=\frac{\left|\sigma_{C}\right|-\left|\sigma_{M}\right|}{\left|\sigma_{M}\right|} \times 100 \%
$$

\subsection{Potentiality in practice}

With the development of industrial technology, it is more and more significant to evaluate and ensure the intrinsic workability of deforming workpiece corresponding to the microstructure evolution and deformation mechanism transformation $^{17}$. One of the most potential applications is FEM, which is popularly used to simulate hot deformation processes and predict the problems in production. In the deforming workpiece the distribution of the strain, strain rate and temperature can be calculated by FEM, and constitutive relation is the basis of numerical simulation. The constitutive model could be applied effectively in computer codes for simulation by two main techniques. As for the first approach, the constitution equation could be applied in FEM by inserting an in-house code using FORTRAN language into the commercial software such as ABAQUS, Marc, etc. As for the second approach, the intensive data predicted by the developed Equation 15 are inputted into the metallic material warehouse of FEM software directly. By contrast, the first

\section{References}

1. Quan GZ, Liu KW and Zhou J. Dynamic softening behaviors of 7075 aluminum alloy. Transactions of nonferrous metals society of China. 2009; 19(s3):s537-s541. http://dx.doi. org/10.1016/S1003-6326(10)60104-5

2. Lin YC, Chen MS and Zhang J. Modeling of flow stress of 40CrMo steel under hot compression. Materials science and engineering A. 2009; 499(1-2):88-92. http://dx.doi. org/10.1016/j.msea.2007.11.119

3. Dan WJ, Zhang WG, Li SH and Lin ZQ. Finite element simulation on strain-induced martensitic transformation effects in TRIP steel sheet forming. Computational materials science. 2007; 39(3): 593-599. http://dx.doi.org/10.1016/j. commatsci.2006.08.013

4. Kim SI, Lee Y and Byon SM. Study on constitutive relation of AISI 4140 steel subject to large strain at elevated temperatures. Materials Processing Technology. 2003; 140(1-3):84-89. http:// dx.doi.org/10.1016/S0924-0136(03)00742-8 method is with higher efficiency and accuracy. However, whether the simulation result is feasible or not depends on the accuracy degree of constitutive models. This improved constitutive model is remarkable for its higher accuracy and can be applied to 7075 aluminum alloy successfully.

\section{Conclusions}

In the present study, the flow behavior of as-extruded 7075 aluminum alloy was investigated using hot compression tests in the temperature range of $573 \sim 723 \mathrm{~K}$ and the strain rate range of $0.01 \sim 10 \mathrm{~s}^{-1}$. The main work is to construct the constitutive description equation for as-extruded 7075 aluminum alloy which represents the relationships of strain, temperature, strain rate and flow stress. The application of improved Arrhenius type model with a series of variable coefficients as functions of true strain (including activation energy of deformation $Q$, material constants a, and $\mathrm{n}$, and structure factor $A$ ) to predict the flow stress during the hot compression of as-extruded 7075 aluminum alloy has been demonstrated in this work. The comparisons between the predicted and experimental results show that, for the worst case, the error in the flow stress estimate is $5.63 \%$, and the max mean error is for a fixed strain rate $3.6 \%$. The developed model provides fast, accurate and consistent results, making it advantageous regarding the conventional Arrhenius type model. In further it can be used in computer code to model the forging response of 7075 aluminum alloy mechanical part members under the prevailing loading conditions.

\section{Acknowledgements}

This work was supported by National Key Technologies R \& D Program of China (2012ZX04010-081), Science and Technology Committee of Chongqing (cstc2009aa3012-1), Fundamental Research Funds for the Central Universities (CDJZR11130009), Sharing Fund of Chongqing University's Large-scale Equipment (2011063014).

5. Berbenni S, Favier V and Berveiller M. Impact of the grain size distribution on the yield stress of heterogeneous materials. Computational materials science. 2007; 24(1):114-142.

6. Shida S. Empirical formula of flow stress of carbon steels resistance to deformation of carbon steels at elevated temperature. 2nd repore. Journal of The JSTP. 1969; 10:610-617.

7. Misaka Y and Yoshimoto T. Formulation of mean resistance of deformation of plain carbon steel at elevated temperature. Journal of the Japan Society for Technology of Plasticity. 1967-1968; 8:414-422.

8. Johnson GR and Cook WH. A constitutive model and data for matals subjected to large strains, high strain rates and high temperature. Proceedings of the Seventh International Symposium on Ballistics. 1983; 541-547.

9. Lee WS, Sue WC, Lin CF and Wu CJ. The strain rate and temperature dependence of the dynamic impact properties of 7075 aluminum alloy. Materials Processing 
Technology. 2000; 100:116-122. http://dx.doi.org/10.1016/ S0924-0136(99)00465-3

10. Jamal AS and Janet T. ANN constitutive model for high strain-rate deformation of Al 7075-T6. Materials Processing Technology. 2007; 186:339-345. http://dx.doi.org/10.1016/j. jmatprotec.2006.11.228

11. Quan GZ, Li GS, Chen T, Wang YX, Zhang YW and Zhou J. Dynamic recrystallization kinetics of $42 \mathrm{CrMo}$ steel during compression at different temperatures and strain rates. Materials Science and Engineering A. 2011; 528(13-14):4643-4651. http://dx.doi.org/10.1016/j.msea.2011.02.090

12. Lei LM, Xu H, Wang MM, Wang L, Qin J, Li H et al. Effect of hot compressive deformation on the martensite transformation of Ti-10V-2Fe-3Al titanium alloy. Materials Science and Engineering A. 2011; 530:591-601. http://dx.doi.org/10.1016/j. msea.2011.10.028

13. Jonas JJ, Sellars CM and Tegart MW. Strength and structure under hot working conditions. International
Metals Reviews. 1969; 14:1-24. http://dx.doi. org/10.1179/095066069790138056

14. Shi H, McLaren AJ, Sellars CM, Shahani R and Bolingbroke R.Constitutive equation for high temperature flow stress of aluminum alloys. Materials Science and Technology. 1997; 13:210216. http://dx.doi.org/10.1179/026708397790302421

15. Zener $\mathrm{C}$ and Hollomon $\mathrm{H}$. Effect of strain-rate upon the plastic flow of steel. Journal of Applied Physics. 1944; 15:22-27. http:// dx.doi.org/10.1063/1.1707363

16. Han MY, Chen ZH, Zhang H and Xia WJ. Flow stress behavior of porous FVS0812 aluminum alloy during hot-compression. Mechanics Research Communications. 2006; 33:508-514. http://dx.doi.org/10.1016/j.mechrescom.2005.05.008

17. Quan GZ, Kang BS, Ku TW and Song WJ. Identification for the optimal working parameters of $\mathrm{Al}-\mathrm{Zn}-\mathrm{Mg}-\mathrm{Cu}$ alloy with the processing maps based on DMM. Advanced manufacturing technology. 2011; 56(9-12):1069-1078. 